Boletín de la Sociedad Geológica Mexicana

VOLUMEN 68, NúM. 2, 2016, P. 373

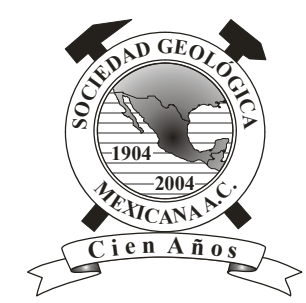

\title{
Addendum
}

\section{The Dolichopodidae (Diptera) of Mexican amber}

\author{
Daniel J. Bickel ${ }^{1, *}$, Mónica M. Solórzano Kraemer² \\ ${ }^{1}$ Entomology Section, Australian Museum, 6 College Street, Sydney NSW 2000 Australia. \\ ${ }^{2}$ Senckenberg Forschungsinstitut und Naturmuseum, Senckenberganlage 25, 60325 Frankfurt am Main, Germany. \\ *danb@austmus.gov.au
}

In the recent paper by Bickel and Solórzano Kraemer (2016) six new species of Dolichopodidae in Mexican amber were published without the Zoobank registration number. The taxa were registered before publication but missed the end phase of edition. Here we add the numbers in order to make the new taxa valid according to the ICZN regulations.

Mesorhaga pseudolacrymans Bickel, n. sp.

urn:lsid:zoobank.org:act:0DE464F6-CA74-4E2F-A193-55FD55E0CDAE

\section{Amblypsilopus monicae Bickel, n. sp.}

urn:1sid:zoobank.org:act:1EBEBAEE-BA24-4610-8C69-BC33BBEF78A8

Medetera amissa Bickel, n. sp.

urn:lsid:zoobank.org:act:0FECE37B-013A-4C8E-B6F3-CBFE0EFD9C87

Medetera totolapa Bickel, n. sp.

urn:lsid:zoobank.org:act:3D9014B1-CB50-40BA-B0C5-3F7D05E4C833
Peloropeodes paleomexicana Bickel, n. sp.

urn:1sid:zoobank.org:act:EF23E260-588E-4FFF-B53A-423055676B5B

Neoparentia chiapensis Bickel, n. sp.

urn:1sid:zoobank.org:act:3C6C6947-523F-4252-8E34-EE7C77757EA

\section{Reference}

Bickel, D.J., Solórzano Kraemer, M.M., 2016, The Dolichopodidae (Diptera) of Mexican amber: Boletín de la Sociedad Geológica Mexicana, 68 (1), 11-21.

Manuscript received: May 12, 2016.

Manuscript accepted: May 13, 2016. 